\title{
Article \\ Concordance of Chronotype Categorisations Based on Dim Light Melatonin Onset, the Morningness-Eveningness Questionnaire, and the Munich Chronotype Questionnaire
}

\author{
Andrew M. Reiter*(D), Charli Sargent and Gregory D. Roach (D) \\ Appleton Institute for Behavioural Science, Central Queensland University, Goodwood, SA 5034, Australia; \\ charli.sargent@cqu.edu.au (C.S.); greg.roach@cqu.edu.au (G.D.R.) \\ * Correspondence: a.reiter@cqu.edu.au
}

Citation: Reiter, A.M.; Sargent, C.; Roach, G.D. Concordance of Chronotype Categorisations Based on Dim Light Melatonin Onset, the Morningness-Eveningness Questionnaire, and the Munich Chronotype Questionnaire. ClocksESleep 2021, 3, 342-350. https://doi.org/10.3390/ clockssleep3020021

Received: 29 April 2021

Accepted: 8 June 2021

Published: 17 June 2021

Publisher's Note: MDPI stays neutral with regard to jurisdictional claims in published maps and institutional affiliations.

Copyright: (C) 2021 by the authors Licensee MDPI, Basel, Switzerland. This article is an open access article distributed under the terms and conditions of the Creative Commons Attribution (CC BY) license (https:// creativecommons.org/licenses/by/ $4.0 /)$.

\begin{abstract}
Chronotype reflects circadian timing and can be determined from biological markers (e.g., dim light melatonin onset; DLMO), or questionnaires (e.g., Morningness-Eveningness Questionnaire; MEQ, or Munich Chronotype Questionnaire; MCTQ). The study's aim was to quantify concordance between chronotype categorisations based on these measures. A total of 72 (36f) young, healthy adults completed the MEQ and MCTQ and provided saliva samples hourly in dim light during the evening in a laboratory. The corrected midpoint of sleep on free days $\left(\mathrm{MSF}_{\mathrm{sc}}\right)$ was derived from $\mathrm{MCTQ}$, and tertile splits were used to define early, intermediate and late DLMO-CT, MEQ-CT and MSF $\mathrm{sc}-\mathrm{CT}$ chronotype categories. DLMO correlated with MEQ score $(r=-0.25, p=0.035)$ and $\mathrm{MSF}_{\mathrm{Sc}}(r=0.32$, $p=0.015)$. For early, intermediate and late DLMO-CT categories, mean(SD) DLMO were 20:25(0:46), 21:33(0:10) and 23:03(0:53). For early, intermediate and late MEQ-CT categories, mean(SD) MEQ scores were 60.5(5.3), 51.4(2.9) and 40.8 (5.0). For early, intermediate and late $\mathrm{MSF}_{\mathrm{Sc}}-\mathrm{CT}$ categories, mean(SD) MSF $_{\text {sc }}$ were 03:23(0:34), 04:37(0:12) and 05:55(0:48). Low concordance of categorisations between DLMO-CT and MEQ-CT (37\%), and between DLMO-CT and $\mathrm{MSF}_{\mathrm{sc}}-\mathrm{CT}(37 \%)$, suggests chronotype categorisations depend on the measure used. To enable valid comparisons with previous results and reduce the likelihood of misleading conclusions, researchers should select measures and statistical techniques appropriate to the construct of interest and research question.
\end{abstract}

Keywords: chronotype; concordance; DLMO; MEQ; MCTQ; categorisation; cut-off; early; intermediate; late

\section{Introduction}

The body clock of each human individual is uniquely timed. Individual differences in body clock timing impact biological rhythms, resulting in a wide range of preferred and actual daily sleep and activity patterns. Chronotype is a construct that reflects individual differences underlying circadian timing [1,2]. Earlier chronotypes get up, achieve peak performance, and go to bed earlier than later chronotypes [3]. Mounting evidence suggests chronotype plays an important role in physical health (e.g., diabetes, metabolic disorders), mental health (e.g., depression, anxiety), and shift-work tolerance [4,5].

Chronobiology researchers have applied varied approaches to the operationalisation and analysis of chronotype for more than one hundred years. Chronotype operationalised as circadian phase or timing can be based on the timing of objective markers in biological variables that exhibit circadian rhythms (e.g., melatonin concentration, core body temperature). Dim light melatonin onset (DLMO) is the most common and reliable circadian phase marker and can be detected in periodic blood, saliva and urine samples [6]. However, collection of biological samples is invasive, laborious, and costly, limiting chronotype determination from objective measures to laboratory experiments with small samples [3]. Self-report questionnaires are simple to administer, and several have been developed to determine circadian preference or typical timing. Chronotype operationalised as preferred 
timing of sleep and activity is usually determined from the Morningness-Eveningness Questionnaire (MEQ) [7]. Chronotype operationalised as the phase of entrainment between the sleep-wake cycle and the 24-h clock can be based on sleep markers sourced from the Munich Chronotype Questionnaire (MCTQ) [8], which incorporates questions about typical times for sleep and activity.

Inconsistency in the approach to the operationalisation of chronotype has stimulated discussion in the literature [1,9]. Whilst chronotype based on objectively-measured biological rhythms is considered appropriate for examination of the impact of circadian timing on outcome variables (e.g., cognitive performance) [10], chronotype based on daily preference is appropriate for research on psychological traits, and chronotype based on the phase of entrainment is appropriate for research on circadian traits that are influenced by the entraining environment [9]. Several studies have assessed relationships between biological rhythms and MEQ/MCTQ measures, e.g., [11-13]. DLMO consistently correlates with both MEQ score and $\mathrm{MSF}_{\mathrm{Sc}}$ (corrected midpoint of sleep on free days derived from the MCTQ), however the strength of correlations varies between populations (e.g., DLMO-MEQ score: $r=-0.40$, DLMO-MSF $\mathrm{sc}: r=0.54$ [14]; DLMO-MEQ score: $r=-0.70$, DLMO-MSF $\mathrm{sc}: r=0.68$ [2]). Although measures of daily preferences and phase of entrainment may correlate, they are not comparable or interchangeable [9]. It follows that any research applying circadian typology should clearly justify the selection of the chronotype definition and measure. Furthermore, to simplify analyses and interpretations, distributions of continuous measures are often stratified into chronotype (e.g., early, intermediate, and late) categories. However, the approach to determining the cut-offs that separate categories is also inconsistent; most researchers apply percentile splits, e.g., [15,16], however, others use self-decided or recommended absolute cut-offs, e.g., [17,18].

Although DLMO, MEQ score and $\mathrm{MSF}_{\mathrm{Sc}}$ correlate, chronotype categorisations based on them do not necessarily concord. An individual may be categorised as early-type based on one measure, but as intermediate or late-type based on another measure. Low concordance between categorisations based on different chronotype measures and arbitrary cut-off scores limit meaningful comparisons of results between studies [1]. Some researchers have sought to mitigate this issue by categorising using a combination of subjective and objective measures, e.g., [19]. A weighted combination of multiple continuous circadian measures may provide more reliable chronotype categorisations, and several approaches have been suggested $[20,21]$.

Surprisingly, there do not appear to be any studies that have systematically quantified concordance between chronotype classifications based on independent, subjective and objective circadian measures [22]. This study will close this gap by quantifying the concordance of chronotype categorisations based on an objective measure (DLMO) with categorisations based on two subjective measures (MEQ and MCTQ), for a relatively large sample of participants. As $\mathrm{MSF}_{\mathrm{sc}}$ (from MCTQ) is a measure of behaviour influenced by circadian timing, we predict greater concordance between DLMO and MCTQ chronotype categorisations than between DLMO and MEQ chronotype categorisations.

\section{Results}

\subsection{DLMO, MEQ Score and $M S F_{S C}$}

The MEQ was completed by each of the 72 participants, and DLMO was available for 71 participants. MSF $_{\mathrm{SC}}$ was calculated for the 57 participants who reported not using an alarm to wake up on free days on the MCTQ. Of these 57 participants, 28 (i.e., 49\%) reported they had regular work schedules. Kolmogorov-Smirnov tests confirmed the DLMO, MEQ score, and $\mathrm{MSF}_{\mathrm{sc}}$ distributions were normal; $D(71)=0.10, p=0.076 ; D(72)=0.066, p=0.200$; $D(57)=0.099, p=0.200$, respectively (Figure 1). Pearson bivariate correlation analyses confirmed DLMO and MEQ score were correlated, $r(71)=-0.25, p=0.035$, DLMO and $\mathrm{MSF}_{\mathrm{Sc}}$ were correlated, $r(57)=0.32, p=0.015$, and MEQ score and $\mathrm{MSF}_{\mathrm{Sc}}$ were correlated, $r(57)=-0.64, p<0.001$ (Figure 2). 

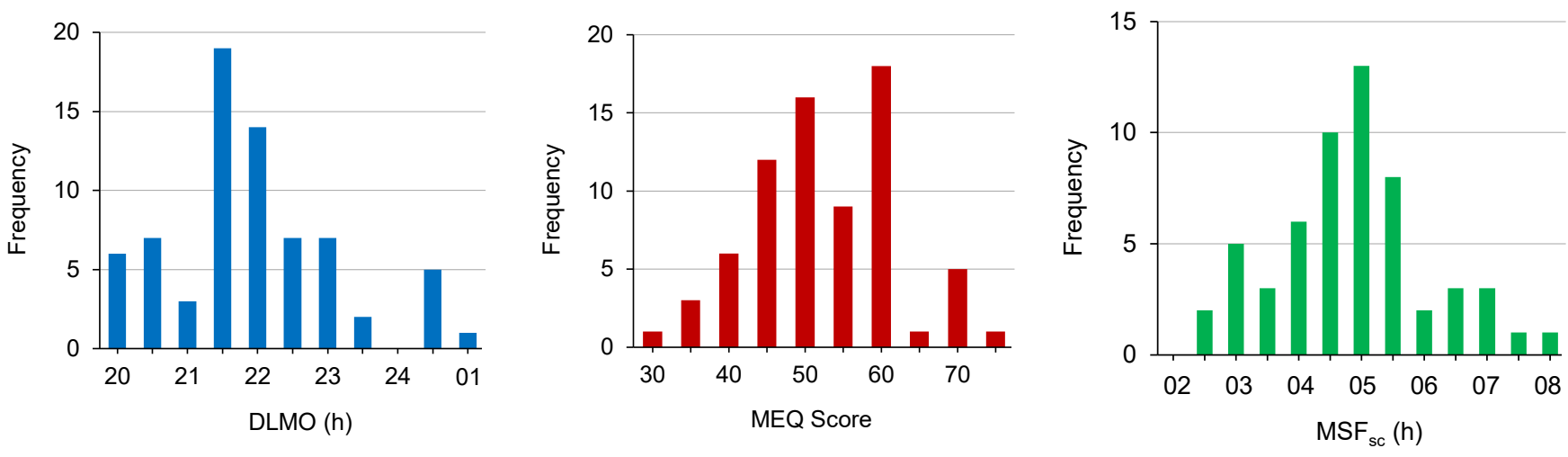

Figure 1. Frequency distributions of DLMO $(n=71)$, MEQ score $(n=72)$, and $\operatorname{MSF}_{\mathrm{sc}}(n=57)$.
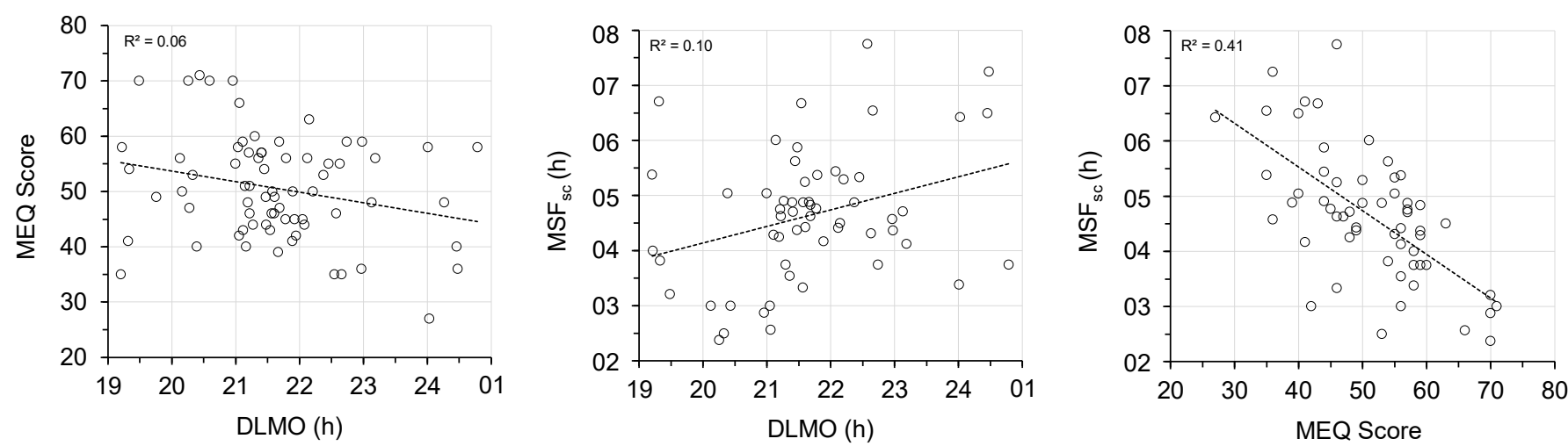

Figure 2. Scatter plots of MEQ score versus DLMO $(n=71), \mathrm{MSF}_{\mathrm{sc}}$ versus DLMO $(n=57)$, and MSF $\mathrm{sc}_{\mathrm{sc}}$ versus MEQ score $(n=57)$.

\subsection{DLMO-CT Categories}

DLMO and MEQ data were available for the 57 participants for which $\mathrm{MSF}_{\mathrm{Sc}}$ could be calculated. The DLMO distribution for this sub-sample was divided into DLMO-CT categories; participants with DLMO earlier than 21:15 were categorised as early DLMO-CT, participants with DLMO later than 21:57 were categorised as late DLMO-CT, and the remaining participants were categorised as intermediate DLMO-CT. The corresponding mean MEQ scores and mean MSF $_{\mathrm{sc}}$ were calculated for each DLMO-CT category (Table 1). A one-way between-groups ANOVA with DLMO-CT as the independent variable revealed no significant effect for MEQ score, $F(2,54)=2.12, p=0.13$, and a significant effect for $\mathrm{MSF}_{\mathrm{Sc}}$, $F(2,54)=4.79, p=0.012$. Post-hoc comparisons using the Games-Howell procedure revealed a difference between the mean $\mathrm{MSF}_{\mathrm{sc}}$ of the early and late categories $(p=0.027)$, but no differences between mean $\mathrm{MSF}_{\mathrm{sc}}$ of the other categories: early-intermediate $(p=0.083)$ and intermediate-late $(p=0.585)$. 
Table 1. Means, standard deviations, and ranges of DLMO, MEQ Score and $\mathrm{MSF}_{\mathrm{Sc}}$ for early, intermediate and late DLMO-CT categories.

\begin{tabular}{|c|c|c|c|c|}
\hline DLMO-CT Category & $n$ & $\begin{array}{c}\text { DLMO (hh:mm) } \\
M(S D), \text { Range }\end{array}$ & $\begin{array}{c}\text { MEQ Score } \\
M(S D), \text { Range }\end{array}$ & $\begin{array}{l}\text { MSF }_{\mathrm{sc}}(\mathrm{hh}: \mathrm{mm}) \\
M(S D), \text { Range }\end{array}$ \\
\hline Early & 19 & $20: 25(0: 46), 19: 12-21: 13$ & $54.8(11.1), 35-71$ & 04:01 (1:15), 02:22-06:42 \\
\hline Intermediate & 19 & $21: 33$ (0:10), 21:16-21:53 & $49.6(6.5), 39-60$ & $04: 46$ (0:47), 03:20-06:40 \\
\hline Late & 19 & 23:03 (0:53), 22:04-00:47 & $49.2(10.1), 27-63$ & 05:07 (1:13), 03:22-07:45 \\
\hline Overall & 57 & $21: 40(1: 16), 19: 12-00: 47$ & $51.2(9.7), 27-71$ & $04: 38(1: 11), 02: 22-07: 45$ \\
\hline
\end{tabular}

\subsection{MEQ-CT and MSFsc-CT Categories}

For the sub-sample of 57 participants, the MEQ and $\mathrm{MSF}_{\mathrm{sc}}$ distributions were each divided into chronotype categories. For the MEQ score distribution, participants with scores greater than or equal to 56 were categorised as early MEQ-CT, participants with scores less than or equal to 46 were categorised as late MEQ-CT, and the remaining participants were categorised as intermediate MEQ-CT (Table 2a). For the $\mathrm{MSF}_{\mathrm{sc}}$ distribution, participants with $\mathrm{MSF}_{\mathrm{sc}}$ earlier than 04:16 h were categorised as early $\mathrm{MSF}_{\mathrm{sc}}-\mathrm{CT}$, participants with $\mathrm{MSF}_{\mathrm{sc}}$ later than 04:53 $\mathrm{h}$ were categorised as late $\mathrm{MSF}_{\mathrm{sc}}-\mathrm{CT}$, and the remaining participants were categorised as intermediate $\mathrm{MSF}_{\mathrm{sc}}-\mathrm{CT}$ (Table 2b).

Table 2. (a) Means, standard deviations, and ranges of MEQ Score for MEQ-CT categories; (b) Means, standard deviations and ranges of $\mathrm{MSF}_{\mathrm{Sc}}$ for $\mathrm{MSF}_{\mathrm{Sc}}-\mathrm{CT}$ categories.

\begin{tabular}{|c|c|c|c|}
\hline \multicolumn{2}{|c|}{ (a) MEQ-CT } & \multicolumn{2}{|c|}{ (b) $\mathrm{MSF}_{\mathrm{sc}}-\mathrm{CT}$} \\
\hline MEQ-CT Category & $\begin{array}{c}\text { MEQ Score } \\
n, M(S D), \text { Range }\end{array}$ & $\mathrm{MSF}_{\mathrm{sc}}-\mathrm{CT}$ Category & $\begin{array}{c}\mathrm{MSF}_{\mathrm{sc}}(\mathrm{hh}: \mathrm{mm}) \\
n, M(S D), \text { Range }\end{array}$ \\
\hline Early & $22,60.5(5.3), 56-71$ & Early & $19,03: 23(0: 34), 02: 22-04: 15$ \\
\hline Intermediate & $15,51.4(2.9), 47-55$ & Intermediate & $19,04: 37$ (0:12), 04:17-04:52 \\
\hline Late & $20,40.8(5.0), 27-46$ & Late & $19,05: 55(0: 48), 04: 54-07: 45$ \\
\hline Overall & $57,51.2(9.7), 27-71$ & Overall & $57,04: 38(1: 11), 02: 22-07: 45$ \\
\hline
\end{tabular}

\subsection{Concordance of Categorisations}

To assess the concordance of categorisations based on the three measures, DLMO$\mathrm{CT}$ categorisations were compared with MEQ-CT and $\mathrm{MSF}_{\mathrm{sc}}-\mathrm{CT}$ categorisations for each participant. The number of participants for each of the nine permutations was tallied (Table 3, Part A). The number of concordances was calculated as the number of participants whose DLMO-CT categorisation matched the subjective measure categorisation (i.e., earlyearly, intermediate-intermediate, late-late). The number of 1-step errors was calculated as the number of participants for which there was a one-category difference between the DLMO-CT category and the subjective measure category (i.e., early-intermediate, intermediate-early, intermediate-late, late-intermediate). The number of 2-step errors was calculated as the number of participants for which there was a two-category difference between the DLMO-CT category and the subjective measure category (i.e., early-late, late-early) (Table 3, Part B). 
Table 3. Part A: Number of participants in each DLMO-CT and MEQ-CT category combination and each DLMO-CT and $\mathrm{MSF}_{\mathrm{sc}}-\mathrm{CT}$ category combination. Part B: Number (percentage) of concordances, 1-step errors and 2-step errors between DLMO-CT and MEQ-CT categorisations and between DLMO-CT and $\mathrm{MSF}_{\mathrm{sc}}-\mathrm{CT}$ categorisations.

\begin{tabular}{|c|c|c|c|c|c|c|c|c|}
\hline \multicolumn{9}{|c|}{ Part A } \\
\hline DLMO-CT & \multicolumn{4}{|c|}{ MEQ-CT Category } & \multicolumn{4}{|c|}{ MSF $_{\text {sc }}-$ CT Category } \\
\hline Category & Early & Intermediate & Late & Total & Early & Intermediate & Late & Total \\
\hline Early & 9 & 5 & 5 & 19 & 8 & 4 & 7 & 19 \\
\hline Intermediate & 6 & 5 & 8 & 19 & 10 & 5 & 4 & 19 \\
\hline Late & 7 & 5 & 7 & 19 & 1 & 10 & 8 & 19 \\
\hline Total & 22 & 15 & 20 & 57 & 19 & 19 & 19 & 57 \\
\hline \multicolumn{9}{|c|}{ Part B } \\
\hline Concordance $^{1}$ & \multirow{3}{*}{\multicolumn{4}{|c|}{$\begin{array}{c}9+5+7=21(37 \%) \\
5+6+8+5=24(42 \%) \\
5+7=12(21 \%)\end{array}$}} & \multicolumn{4}{|c|}{$8+5+8=21(37 \%)$} \\
\hline 1 -step errors ${ }^{2}$ & & & & & \multicolumn{4}{|c|}{$4+10+4+10=28(49 \%)$} \\
\hline 2 -step errors ${ }^{3}$ & & & & & \multicolumn{4}{|c|}{$7+1=8(14 \%)$} \\
\hline Total & \multicolumn{4}{|c|}{$57(100 \%)$} & \multicolumn{4}{|c|}{$57(100 \%)$} \\
\hline
\end{tabular}

${ }^{1}$ Concordance: Agreement between DLMO-CT categorisation and subjective measure categorisation. ${ }^{2}$ 1-step error: One category difference between DLMO-CT categorisation and subjective measure categorisation (i.e., early or late DLMO-CT categorisation, and intermediate categorisation based on the other measure, and vice versa). ${ }^{3}$ 2-step error: Two category difference between DLMO-CT category and subjective measure category (i.e., early (late) DLMO-CT categorisation and late (early) categorisation based on the other measure and vice versa).

\section{Discussion}

For this sample of young, healthy adults, the continuous measures of DLMO, MEQ score and $\mathrm{MSF}_{\mathrm{sc}}$ were normally distributed and correlated. Circadian questionnaires such as the MEQ and MCTQ are simple and suited to the field and large-scale studies, but their measures are not interchangeable with each other, or with DLMO. DLMO was more strongly correlated with $\mathrm{MSF}_{\mathrm{sc}}$ than MEQ score, although neither correlation is strong. $\mathrm{MSF}_{\mathrm{sc}}$, a subjective measure of sleep timing, appears more closely related to endogenous circadian timing than the subjective preference for sleep timing measured by MEQ [2]. The correlation between DLMO and MEQ score $(r=-0.25)$ is weaker than the same correlation reported for other studies $(r=-0.35$ to -0.76$)$ [23]. The correlation between DLMO and $\operatorname{MSF}_{\mathrm{sc}}(r=0.32)$ may be weaker than the same correlation reported by others $(r=0.54$ [14], $r=0.68$ [2]) because our participants were mostly international travellers or students. Application of the MCTQ to individuals with irregular work arrangements may be problematic, as its calculations assume structured work schedules [24]. Furthermore, chronotype can only be determined from the MCTQ when an alarm clock is not used on free days [25], and therefore MEQ is sometimes used in preference to MCTQ simply to maximise available data, e.g., [26]. In the present study, $\mathrm{MSF}_{\mathrm{sc}}$ could not be calculated for 14 participants, reducing our sample to 57 . A recently developed short-form of MCTQ ( $\mu \mathrm{MCTQ}$ ) allows $\mathrm{MSF}_{\mathrm{sc}}$ to be calculated for all respondents by capturing wake times only on free days on which an alarm clock is not used [27], and a similar modification to the standard MCTQ may enhance its utility.

For chronotype categorisations based on DLMO, there were no differences in mean MEQ scores between each category, and only a difference in mean $\mathrm{MSF}_{\mathrm{sc}}$ between the early and late categories. This suggests that for this sample, MEQ scores and $\mathrm{MSF}_{\mathrm{sc}}$ of participants in the early, intermediate, and late chronotype categories based on DLMO were indistinguishable. Chronotype categorisations based on splits of both the MEQ score distribution and the $\mathrm{MSF}_{\mathrm{sc}}$ distribution had low concordance with chronotype categorisations based on a split of the DLMO distribution. Compared with categorisations based on $\mathrm{DLMO}$, concordance for categorisations based on both MEQ score and $\mathrm{MSF}_{\mathrm{sc}}$ was $37 \%$ (i.e., $63 \%$ error rate). However, categorisations based on the MEQ score had a greater proportion of 2-step errors (21\%) than categorisations based on $\mathrm{MSF}_{\mathrm{sc}}(14 \%)$. The low concordance may be a consequence of applying percentile splits to normally distributed continuous variables to create a categorical variable. This approach allows for the use of ANOVA statistical methods that simplify analyses and interpretation of differences between groups. 
A shortcoming of this methodology is that participants with measures near, but below or above, the percentile cut-offs can be assigned to different categories, although their measures are actually closer to each other than other members of their assigned category. Secondly, percentile splits of each study sample will yield different thresholds, limiting the generalisability of the results and comparisons with other studies. Although samples are sometimes dichotomised by a median split, e.g., [26], trichotomisation by tertile split, as in the present study, should provide superior between-group comparisons. The risk of drawing incorrect conclusions arising from categorisations based on continuous measures can usually be mitigated or overcome by regression and correlational analysis [28].

An important limitation of this study is that extreme chronotypes were excluded due to the selection criteria for the main shift work-study. However, our findings are generalisable to populations of younger, healthy adults, as epidemiological studies report that extreme chronotypes are uncommon [29]. Mean DLMO of our early and late DLMO chronotype categories (20:25 h and 23:03 h respectively) are comparable with criteria applied in other studies (e.g., early: $<21: 30 \mathrm{~h}$, late $>22.30 \mathrm{~h}$ [20]), indicating our sample included a broad range of chronotypes. We demonstrated greater concordance between categorisations based on DLMO and categorisations based on each of the subjective measures for the early and late categories than for the intermediate category, suggesting concordance may be greater with more extreme chronotypes. A second limitation to our study is that to illustrate the underlying measurement issue, we divided our sample into chronotype categories using tertile splits. Although this method is commonly used by chronotype researchers, categorisations based on other arbitrary or recommended percentiles or absolute cut-offs would likely yield different levels of categorisation concordance.

Valid measurement is a key element of scientific research. Our results suggest that laboratory experimental research on the differential effects of body clock timing on outcome variables should use objective biological measures where possible. DLMO, MEQ and MCTQ measure related, but different constructs that are not interchangeable. Although these measures were correlated for this sample, the correlations were not strong. Consequently, chronotype categorisations based on percentile splits of these distributions showed low concordance. To enable valid comparisons with previous results and reduce the likelihood of misleading conclusions, chronotype researchers should select the most appropriate measures and statistical techniques for their construct of interest and research question.

\section{Materials and Methods}

\subsection{Participants}

Data were collected during a simulated shift work-study conducted at the Appleton Institute in Adelaide, South Australia. Participants were 72 young, healthy adults (36 females, 36 males) with a mean $( \pm S D$ ) age of 23.1 ( \pm 3.6) years and body mass index (BMI) of $21.5( \pm 1.9) \mathrm{kg} / \mathrm{m}^{2}$, recruited by advertisements posted at hostels, student accommodation and university campuses and on casual employment websites. Screening involved the completion of a general health questionnaire and an in-person interview. Key inclusion criteria included age (18-30 years), BMI (18-25 kg/m²) and good physical and mental health. Key exclusion criteria included smoking, use of medications (excluding oral contraceptives), use of recreational drugs, excessive alcohol or caffeine consumption, excessive exercise and shift work or transmeridian travel during the month prior to the study. Participants were mostly international travellers or students, provided written informed consent and were financially compensated with an honorarium.

\subsection{Procedure}

Data for this study were collected during the first two days of a multi-day laboratory shift work-study. During the week before the study, participants were requested to maintain their normal sleep patterns, complete a sleep diary, and wear an activity monitor on their non-dominant wrist. In the laboratory, each participant was accommodated with their own bedroom and bathroom. Days 1 and 2 were work-free days. On Day 1, participants en- 
tered the laboratory at 16:00 and were provided with a 9-h sleep opportunity (23:00-08:00). On Day 2, participants completed the MEQ and MCTQ and were familiarised with the simulated shift-work tasks between periods of free time. Nine saliva samples were then collected from each participant hourly in dim light (<10 lux) (19:00-03:00). Twenty minutes before each sample was collected, participants were instructed to gently rinse their mouths with water, remain seated, and refrain from eating and drinking until after the sample was collected. To collect saliva, participants rolled a cotton swab in their mouths for approximately 2-3 min. Swabs were refrigerated prior to centrifuging and freezing at $-20{ }^{\circ} \mathrm{C}$. After saliva sampling, participants were provided a 9-h sleep opportunity (03:00-12:00).

\subsection{Measures}

\subsubsection{Dim Light Melatonin Onset (DLMO)}

DLMO was determined from saliva collected using cotton swabs (Salivette; Sarstedt, Nümbrecht, Germany). Melatonin concentration was measured by 4.3 pM direct radioimmunoassay, using reagents from Buhlmann Laboratories AG (Allschwill, Switzerland). DLMO was defined as the time melatonin concentration reached a fixed threshold of $10 \mathrm{pM}$ and stayed above this threshold for at least two subsequent samples [30]. For one participant, whose melatonin concentration was above $10 \mathrm{pM}$ for all samples, a higher relative threshold equal to the mean of the first three melatonin concentration values plus two standard deviations of those values was used [30]. Linear interpolation was applied to estimate the time of DLMO between the sample times immediately before and after concentration exceeded the threshold.

\subsubsection{Morningness-Eveningness Questionnaire}

The Morningness-Eveningness Questionnaire (MEQ) [7] is the most commonly used circadian typology questionnaire and consists of 19 questions with Likert responses about an individual's preferred bedtimes, get-up times, and times for activity [22]. Responses to questions are scored and summed to produce an overall morningness score ranging from 16 to 86, with higher scores indicating greater morningness [7].

\subsubsection{Munich Chronotype Questionnaire}

The Munich Chronotype Questionnaire(MCTQ) [8] incorporates 14 questions about the timing of sleep and activity on work and free days. Responses can be used to assess work schedule, the timing of sleep and alarm clock use on work and free days and the number of days worked per week [31]. The midpoint of sleep on free days (MSF) can be extracted from the MCTQ and used to determine chronotype [8]. The premise of using MSF to determine chronotype is that an individual's sleep and wake timing on free days corresponds to their circadian timing, with earlier MSF corresponding with earlier chronotype [15]. MSF is calculated as the sleep onset on free days $\left(\mathrm{SO}_{\mathrm{f}}\right)$, plus half the sleep duration on free days $\left(\mathrm{SD}_{\mathrm{f}}\right)$. As most individuals accumulate a sleep debt during the working week and extend their sleep on free days, MSF can be "sleep-corrected" to MSF sc the corrected sleep midpoint on free days. $\mathrm{MSF}_{\mathrm{sc}}$ is calculated as MSF minus a correction for sleep debt equal to half the difference between sleep duration on free days $\left(\mathrm{SD}_{\mathrm{f}}\right)$ and average sleep duration over the week $\left(\mathrm{SD}_{\text {week }}\right)$, which is only applied if sleep duration on free days is greater than sleep duration on workdays [24]. An important limitation of the MCTQ is that individuals who use an alarm to wake up on free days cannot be chronotyped, as their MSF may be impacted and therefore not reflect internal timing [25].

\subsection{Statistical Analyses}

Data were analysed using IBM SPSS Statistics for Windows, Version 26.0 (Armonk, NY, USA), with statistical significance, determined using an alpha level of 0.05 . KolmogorovSmirnov tests were used to assess the normality of the DLMO, MEQ and MSF Sc $_{\text {distribu- }}$ tions. Pearson pairwise bivariate correlation analyses were used to assess relationships between DLMO, MEQ and $\mathrm{MSF}_{\mathrm{sc}}$. Consistent with the approach recommended for com- 
paring chronotypes based on mid-sleep times derived from MCTQ within a sample [32], the DLMO, MEQ and $\mathrm{MSF}_{\mathrm{sc}}$ distributions were each divided into early, intermediate and late DLMO-CT, MEQ-CT, and $\mathrm{MSF}_{\mathrm{sc}}-\mathrm{CT}$ categories by applying tertile splits.

Author Contributions: Conceptualization: A.M.R.; methodology: A.M.R., G.D.R. and C.S.; formal analysis: A.M.R.; data curation: C.S.; writing—original draft: A.M.R.; writing—review and editing: G.D.R. and C.S. All authors have read and agreed to the published version of the manuscript.

Funding: This research was funded by the Australian Research Council (ARC) under Grant DP160104909.

Institutional Review Board Statement: The study was conducted according to the guidelines of the Declaration of Helsinki and approved by the Central Queensland University Human Research Ethics Committee (Approval Number: H16/06-168, October 2016).

Informed Consent Statement: Informed consent was obtained from all subjects involved in the study.

Data Availability Statement: The data for this study are not currently publicly available as they are part of a larger dataset that will be used for another purpose.

Acknowledgments: The authors thank the study participants and the technical staff at Appleton Institute.

Conflicts of Interest: The authors declare no conflict of interest.

\section{References}

1. Levandovski, R.; Sasso, E.; Hidalgo, M.P. Chronotype: A review of the advances, limits and applicability of the main instruments used in the literature to assess human phenotype. Trends Psychiatry Psychother 2013, 35, 3-11. [CrossRef]

2. Kantermann, T.; Sung, H.; Burgess, H.J. Comparing the Morningness-Eveningness Questionnaire and Munich ChronoType Questionnaire to the Dim Light Melatonin Onset. J. Biol. Rhythms 2015, 30, 449-453. [CrossRef]

3. Adan, A.; Archer, S.N.; Hidalgo, M.P.; Di Milia, L.; Natale, V.; Randler, C. Circadian typology: A comprehensive review. Chronobiol. Int. 2012, 29, 1153-1175. [CrossRef] [PubMed]

4. Fabbian, F.; Zucchi, B.; De Giorgi, A.; Tiseo, R.; Boari, B.; Salmi, R.; Cappadona, R.; Gianesini, G.; Bassi, E.; Signani, F.; et al. Chronotype, gender and general health. Chronobiol. Int. 2016, 33, 863-882. [CrossRef]

5. Juda, M.; Vetter, C.; Roenneberg, T. Chronotype modulates sleep duration, sleep quality, and social jet lag in shift-workers. J. Biol. Rhythms 2013, 28, 141-151. [CrossRef] [PubMed]

6. Burgess, H.J.; Eastman, C.I. The dim light melatonin onset following fixed and free sleep schedules. J. Sleep Res. 2005, 14, $229-237$. [CrossRef] [PubMed]

7. Horne, J.A.; Ostberg, O. A self-assessment questionnaire to determine morningness-eveningness in human circadian rhythms. Int. J. Chronobiol. 1976, 4, 97-110. [PubMed]

8. Roenneberg, T.; Wirz-Justice, A.; Merrow, M. Life between clocks: Daily temporal patterns of human chronotypes. J. Biol. Rhythms 2003, 18, 80-90. [CrossRef]

9. Roenneberg, T. Having trouble typing? What on earth is chronotype? J. Biol. Rhythms 2015, 30, 487-491. [CrossRef]

10. Ritchie, H.K.; Burke, T.M.; Dear, T.B.; McHill, A.W.; Axelsson, J.; Wright, K.P., Jr. Impact of sleep inertia on visual selective attention for rare targets and the influence of chronotype. J. Sleep Res. 2017, 26, 551-558. [CrossRef]

11. Hida, A.; Kitamura, S.; Ohsawa, Y.; Enomoto, M.; Katayose, Y.; Motomura, Y.; Moriguchi, Y.; Nozaki, K.; Watanabe, M.; Aritake, S.; et al. In vitro circadian period is associated with circadian/sleep preference. Sci. Rep. 2013, 3, 2074. [CrossRef]

12. Brown, S.A.; Kunz, D.; Dumas, A.; Westermark, P.O.; Vanselow, K.; Tilmann-Wahnschaffe, A.; Herzel, H.; Kramer, A. Molecular insights into human daily behavior. Proc. Natl. Acad. Sci. 2008, 105, 1602-1607. [CrossRef]

13. Ferrante, A.; Gellerman, D.; Ay, A.; Woods, K.P.; Filipowicz, A.M.; Jain, K.; Bearden, N.; Ingram, K.K. Diurnal preference predicts phase differences in expression of human peripheral circadian clock genes. J. Circadian Rhythms 2015, 13. [CrossRef]

14. Kitamura, S.; Hida, A.; Aritake, S.; Higuchi, S.; Enomoto, M.; Kato, M.; Vetter, C.; Roenneberg, T.; Mishima, K. Validity of the Japanese version of the Munich ChronoType Questionnaire. Chronobiol. Int. 2014, 31, 845-850. [CrossRef] [PubMed]

15. Ritonja, J.; Tranmer, J.; Aronson, K.J. The relationship between night work, chronotype, and cardiometabolic risk factors in female hospital employees. Chronobiol. Int. 2019, 36, 616-628. [CrossRef]

16. Vetter, C.; Fischer, D.; Matera, J.L.; Roenneberg, T. Aligning work and circadian time in shift workers improves sleep and reduces circadian disruption. Curr. Biol. 2015, 25, 907-911. [CrossRef] [PubMed]

17. Caci, H.; Deschaux, O.; Adan, A.; Natale, V. Comparing three morningness scales: Age and gender effects, structure and cut-off criteria. Sleep Med. 2009, 10, 240-245. [CrossRef]

18. Kervezee, L.; Gonzales-Aste, F.; Boudreau, P.; Boivin, D.B. The relationship between chronotype and sleep behavior during rotating shift work: A field study. Sleep 2021. [CrossRef]

19. Breithaupt, H.; Hildebrandt, G.; D HRE, D.; Josch, R.; Sieber, U.; Werner, M. Tolerance to shift of sleep, as related to the individual's circadian phase position. Ergonomics 1978, 21, 767-774. [CrossRef] [PubMed] 
20. Facer-Childs, E.R.; Middleton, B.; Bagshaw, A.P.; Skene, D.J. Human Circadian Phenotyping and Diurnal Performance Testing in the Real World. JoVE 2020, e60448. [CrossRef]

21. Smith, C.S.; Reilly, C.; Midkiff, K. Evaluation of three circadian rhythm questionnaires with suggestions for an improved measure of morningness. J. Appl. Psychol. 1989, 74, 728. [CrossRef]

22. Di Milia, L.; Adan, A.; Natale, V.; Randler, C. Reviewing the psychometric properties of contemporary circadian typology measures. Chronobiol. Int. 2013, 30, 1261-1271. [CrossRef]

23. Sack, R.L.; Auckley, D.; Auger, R.R.; Carskadon, M.A.; Wright, K.P., Jr.; Vitiello, M.V.; Zhdanova, I.V.; American Academy of Sleep, M. Circadian rhythm sleep disorders: Part I, basic principles, shift work and jet lag disorders. An American Academy of Sleep Medicine review. Sleep 2007, 30, 1460-1483. [CrossRef]

24. Roenneberg, T.; Pilz, L.K.; Zerbini, G.; Winnebeck, E.C. Chronotype and Social Jetlag: A (Self-) Critical Review. Biology 2019, 8. [CrossRef] [PubMed]

25. Roenneberg, T.; Allebrandt, K.V.; Merrow, M.; Vetter, C. Social jetlag and obesity. Curr Biol 2012, 22, 939-943. [CrossRef] [PubMed]

26. Thomas, J.M.; Kern, P.A.; Bush, H.M.; McQuerry, K.J.; Black, W.S.; Clasey, J.L.; Pendergast, J.S. Circadian rhythm phase shifts caused by timed exercise vary with chronotype. JCI Insight 2020, 5. [CrossRef]

27. Ghotbi, N.; Pilz, L.K.; Winnebeck, E.C.; Vetter, C.; Zerbini, G.; Lenssen, D.; Frighetto, G.; Salamanca, M.; Costa, R.; Montagnese, S.; et al. The $\mu$ MCTQ: An Ultra-Short Version of the Munich ChronoType Questionnaire. J. Biol. Rhythms 2020, 35, 98-110. [CrossRef]

28. MacCallum, R.C.; Zhang, S.; Preacher, K.J.; Rucker, D.D. On the practice of dichotomization of quantitative variables. Psychol. Methods 2002, 7, 19-40. [CrossRef] [PubMed]

29. Roenneberg, T.; Kuehnle, T.; Juda, M.; Kantermann, T.; Allebrandt, K.; Gordijn, M.; Merrow, M. Epidemiology of the human circadian clock. Sleep Med. Rev. 2007, 11, 429-438. [CrossRef] [PubMed]

30. Voultsios, A.; Kennaway, D.J.; Dawson, D. Salivary melatonin as a circadian phase marker: Validation and comparison to plasma melatonin. J. Biol. Rhythms 1997, 12, 457-466. [CrossRef]

31. Burgess, H.J.; Kikyo, F.; Valdespino-Hayden, Z.; Rizvydeen, M.; Kimura, M.; Pollack, M.H.; Hobfoll, S.E.; Rajan, K.B.; Zalta, A.K.; Burns, J.W. Do the Morningness-Eveningness Questionnaire and Munich ChronoType Questionnaire Change After Morning Light Treatment? Sleep Sci. Pract. 2018, 2, 12. [CrossRef] [PubMed]

32. Roenneberg, T.; Keller, L.K.; Fischer, D.; Matera, J.L.; Vetter, C.; Winnebeck, E.C. Human activity and rest in situ. In Methods Enzymol; Elsevier: Amsterdam, The Netherlands, 2015; Volume 552, pp. 257-283. 